Check for updates

Cite this: Chem. Sci., 2019, 10, 4890

๑ All publication charges for this article have been paid for by the Royal Society of Chemistry

Received 21st January 2019

Accepted 2nd April 2019

DOI: $10.1039 / \mathrm{c} 9 \mathrm{sc} 00342 \mathrm{~h}$

rsc.li/chemical-science

\section{Synthesis of a one-handed helical polythiophene: a new approach using an axially chiral bithiophene with a fixed syn-conformation $\uparrow$}

\author{
Tomoyuki Ikai, (D) *a Kokoro Takayama, ${ }^{a}$ Yuya Wada, ${ }^{a}$ Serena Minami, ${ }^{a}$ \\ Chanokporn Apiboon (D) and Ken-ichi Shinohara (D) ${ }^{\mathrm{b}}$
}

\begin{abstract}
We report an optically active polythiophene capable of forming a one-handed helically folded conformation without needing aggregate formation, poor solvent conditions, hydrogen-bonded ion-pair formation or guest addition. The target polythiophene (poly- $T_{R}$ ) with a static axial chirality in the main chain was synthesized via Stille coupling copolymerization of a glucose-linked chiral 5,5'dibromobithiophene with 2,5-bis(stannyl)thiophene. Poly- $T_{R}$ showed a characteristic circular dichroism and circularly polarized luminescence, which were completely different to those observed for an analogous polymer (poly- $\mathrm{Ph}_{\mathrm{R}}$ ) and the corresponding unimer/dimer model compounds. This chiroptical study, combined with the results of all-atom molecular dynamics simulations, revealed that poly- $\mathrm{T}_{\mathrm{R}}$ can fold into a left-handed helical conformation under good solvent conditions. Partial conformational regulation derived from the fixed syn-conformation of the chiral bithiophene unit was considered a key factor in producing the one-handed helical polythiophene.
\end{abstract}

\section{Introduction}

A simple poly(thiophene-2,5-diyl) without any pendant groups was successfully synthesized via chemical polymerization in $1980 .^{1,2}$ In the last four decades, much research effort has been focused on developing a range of functional polythiophenes (herein referring to poly(thiophene-2,5-diyl)s, unless otherwise noted) using various polymerization techniques and/or postpolymerization modifications. ${ }^{3-9}$ Polythiophenes are now recognized as an important class of $\pi$-conjugated polymers and have been extensively studied for applications in organic devices and functional materials, including as photovoltaics, field-effect transistors, light emitting diodes, magneto-optics, actuators and chemical/biological sensors. ${ }^{10-15}$ This practical utility arises from their excellent semiconducting, optical and magnetic features, in addition to substantial environmental stability and mechanical strength.

Chiral polythiophenes containing optically active components somewhere in the molecular structures have also attracted considerable attention in the fields of supramolecular

${ }^{a}$ Graduate School of Natural Science and Technology, Kanazawa University, Kakuma-machi, Kanazawa 920-1192,Japan.E-mail: ikai@se.kanazawa-u.ac.jp ${ }^{b}$ School of Materials Science, Japan Advanced Institute of Science and Technology (JAIST), 1-1 Asahi-dai, Nomi 923-1292, Japan

$\dagger$ Electronic supplementary information (ESI) available: Detailed experimental procedures, characterizations of molecules/polymers and additional spectroscopic, chromatographic and computational data. See DOI: 10.1039/c9sc00342h chemistry, because these polymers can easily self-assemble into helical aggregates through intermolecular $\pi-\pi$ interactions under poor solvent conditions or in a properly treated film. ${ }^{16-22}$ These supramolecular chiral aggregates often show more intense chiroptical properties (that is, optical rotation, circular dichroism (CD) and circularly polarized luminescence (CPL)) than those in a molecularly dispersed state. On the other hand, Cui et al. have predicted the possible existence of a helically folded polythiophene through semi-empirical calculations. ${ }^{23}$ In fact, several groups have succeeded in preparing chiral polythiophenes with macromolecular helicity rather than supramolecular helicity. Wennerström and Inganäs et al. reported that polythiophenes bearing ionic pendant groups could form a one-handed helical conformation in aqueous solutions, where hydrogen-bonded ionpair formations within the polymer chain played important roles in helix formation. ${ }^{24-27}$ Shinkai et al. and Inganäs et al. found that a helical conformation was induced in ionic polythiophenes upon complexation with guest molecules and polymers. ${ }^{28-35}$ Meijer et al. and Koeckelberghs et al. also reported nonionic helical polythiophenes that could fold only under poor solvent conditions containing water or methanol, probably due to hydrophobic interactions. ${ }^{36,37}$ Furthermore, ortho-linked polythiophenes, poly(thiophene-2,3-diyl)s, can adopt a helical conformation, as evidenced by scanning tunneling microscopy imaging, although helicity control was not achieved owing to an achiral molecular design.$^{38}$ In each case, specific environments or situations have been required to provide polythiophene backbones with macromolecular helicity, while helix formation has not been achieved in a molecularly dispersed state under good solvent conditions. The 
environment-independent helix-forming feature of polythiophenes is advantageous from a practical perspective, because careful consideration of extrinsic influences, such as concentration, temperature and solvent, is not required, which simplifies device manufacture and expands the application possibilities.

Recently, we synthesized a series of optically active $\pi$ conjugated polymers, poly(arylene ethynylene)s, containing a Dglucose-linked biaryl unit as a key structural element in the main chain. ${ }^{39-43}$ We demonstrated that some of these polymers possessing favorable combinations of backbone and pendant structures folded into helical conformations with a preferredhandedness. In this work, we report a new synthetic approach to one-handed helical polythiophene using the fixed synconformation of a D-glucose-linked bithiophene unit with static axial chirality (Fig. 1). ${ }^{41}$ The one-handed helix formation of the resulting polythiophene in a molecularly dispersed state, particularly under good solvent conditions, was investigated using both chiroptical analysis under various conditions and an all-atom molecular dynamics (MD) study.

\section{Results and discussion}

\section{Synthesis}

The synthetic routes used to prepare optically active bithiophene monomer $(\mathrm{a} R)-\mathbf{3}$ and $\pi$-conjugated polymers poly- $\mathrm{T}_{\mathrm{R}}$ and poly- $\mathrm{Ph}_{\mathrm{R}}$ are summarized in Fig. 2. Monomer $(\mathrm{a} R$ )-3, containing point and axial chirality derived from glucose and biaryl units, respectively, was synthesized from a previously reported $5,5^{\prime}$ dibromobithiophene derivative, $(\mathrm{a} R)-\mathbf{1} \mathbf{1}^{\mathbf{4 1}}$ through acetal deprotection followed by esterification at the 4-and 6-positions of the glucose unit. The obtained $(\mathrm{a} R)-\mathbf{3}$ was copolymerized with $\mathbf{4}$ or 5 via Stille coupling in toluene/ $N, N$-dimethylformamide $(4: 1, \mathrm{v} / \mathrm{v})$ at $110{ }^{\circ} \mathrm{C}$. The optically active polymers, poly- $\mathrm{T}_{\mathrm{R}}$ and poly- $\mathrm{Ph}_{\mathrm{R}}$, containing 2,5-thienylene and $p$-phenylene comonomer units, respectively, were obtained in moderate yields (>57\%), with molecular masses $\left(M_{\mathrm{n}}\right)$ greater than $5.6 \times 10^{3} \mathrm{~g} \mathrm{~mol}^{-1}$, as estimated by size-exclusion chromatography (SEC). The copolymerization of $\mathbf{4}$ and $(\mathrm{a} S)-\mathbf{3}$, a diastereomer of $(\mathrm{a} R)-\mathbf{3}$ with opposite axial chirality (see Chart 1), was also performed using the same method. However, as the resulting poly- $\mathrm{T}_{\mathrm{S}}$ was almost insoluble in common organic solvents, including chloroform and tetrahydrofuran, it could not be further characterized. Monomeric model compounds model- $\mathrm{T}_{\mathrm{R}}$ and model- $\mathrm{Ph}_{\mathrm{R}}(\mathrm{Chart}$

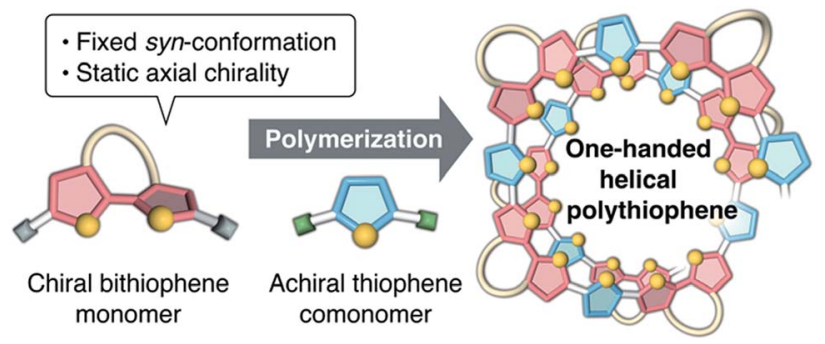

Fig. 1 Schematic illustration of the synthetic approach to one-handed helical polythiophene using the fixed syn-conformation of a chiral bithiophene with static axial chirality.

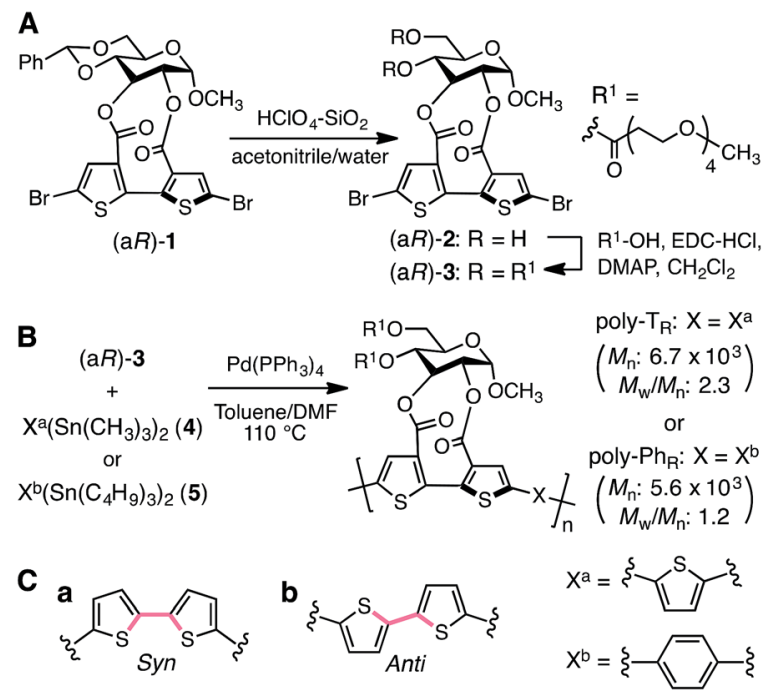

Fig. 2 Synthesis of (A) optically active bithiophene monomer $(\mathrm{a} R)-3$ and (B) $\pi$-conjugated polymers poly- $\mathrm{T}_{\mathrm{R}}$ and poly- $\mathrm{Ph}_{\mathrm{R}}$. (C) Syn- (a) and anti- (b) conformations of a bithiophene unit.

1), related to poly- $\mathrm{T}_{\mathrm{R}}$ and poly- $\mathrm{Ph}_{\mathrm{R}}$, respectively, were synthesized for comparative studies (Scheme S1†).

\section{Chiroptical properties}

$\mathrm{CD}$ and absorption spectra of the monomer, unimer models and polymers in chloroform are shown in Fig. 3. Poly- $\mathrm{T}_{\mathrm{R}}$ showed a clear bisignated Cotton effect in the absorption region of the polymer backbone (400-580 nm) and its CD intensity was much larger than those observed for $(\mathrm{a} R)-\mathbf{3}$ and the corresponding model- $\mathrm{T}_{\mathrm{R}}$. Although the absorption regions were different due to differing $\pi$-conjugation lengths and a simple comparison was difficult, this CD comparison indicated that the characteristic Cotton effect observed for poly- $\mathrm{T}_{\mathrm{R}}$ did not arise from only the chirality of the D-glucose-based monomeric unit. Considering the chiroptical investigation of previously reported chiral polythiophenes, ${ }^{16}$ the poly- $\mathrm{T}_{\mathrm{R}}$ 's CD was presumed to derive from either supramolecular chirality induced in the polymer aggregate or conformational chirality induced in a single polymer chain with a regular higher-order structure. To gain further insight into the CD origin, we performed chiroptical measurements of poly- $T_{R}$ under several conditions. When the poly- $T_{R}$ concentration in chloroform was varied in the range of 0.01$1.0 \mathrm{mM}$, almost no concentration dependence was observed in the (chir)optical properties (Fig. S1 $\dagger$ ). Furthermore, the absorbance and CD intensities in chloroform did not change after passing through a membrane filter with a pore size of $0.20 \mu \mathrm{m}$ (Fig. S2 $\dagger$ ). These results suggested that the intense CD signal of poly- $T_{R}$ was derived from a specific secondary structural formation within a single polymer chain, rather than the formation of polymer aggregates through intermolecular interactions. Notably, the bisignated CD spectral pattern of poly- $T_{R}$ closely resembled those of previously reported polythiophenes with one-handed helical conformations, ${ }^{24-27}$ in which all torsion angles between thiophene rings were regulated to a syn-conformation, as shown in Fig. 2C(a). Therefore, 


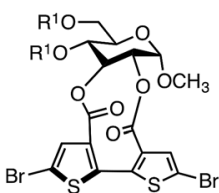

(aS)-3
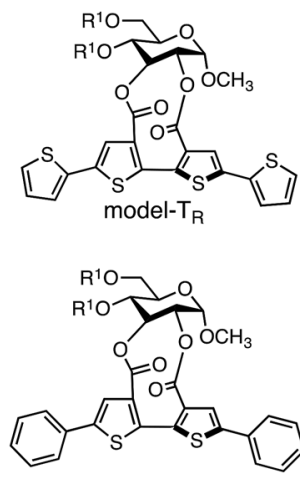

model-Ph
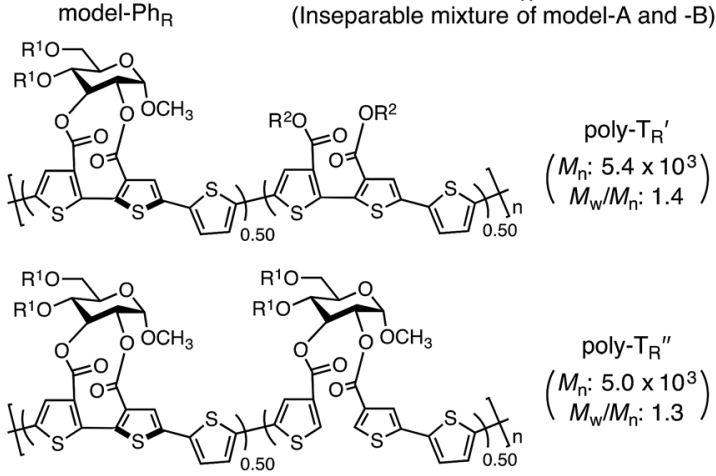

Chart 1
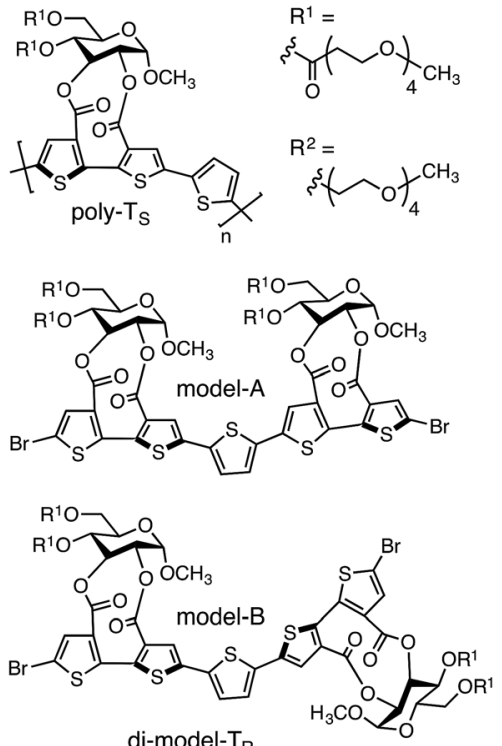

di-model- $T_{\mathrm{A}}$ B) 
whose backbone conformation was mostly maintained regardless of the exterior environmental conditions, such as concentration, temperature and solvent. In sharp contrast, poly- $\mathrm{Ph}_{\mathrm{R}}$ showed a relatively weak CD signal with an intensity and pattern comparable to those of the corresponding model- $\mathrm{Ph}_{\mathrm{R}}$ (Fig. 3). Furthermore, the chiroptical property of $\operatorname{poly}^{-} \mathrm{Ph}_{\mathrm{R}}$ was almost independent on the molecular mass (Fig. S6†), suggesting that the poly- $\mathrm{Ph}_{\mathrm{R}}$ backbone did not form a specific higher-order structure. As we have previously reported for an analogous glucose-linked poly(arylene ethynylene), ${ }^{45}$ the phenylene units might not provide enough cooperative $\pi-\pi$ interactions within the main chains, which are necessary to stabilize the helix structure. Poly- $T_{R}$ analogues, poly- $\mathrm{T}_{\mathrm{R}}^{\prime}$ and poly- $\mathrm{T}_{\mathrm{R}}^{\prime \prime}$ (see Chart 1), which contained an achiral bithiophene unit capable of free internal rotation and a $\mathrm{D}^{-}$ glucose-appended unit without a covalent bond between thiophene rings, respectively, did not show apparent CD signals (Fig. $\mathrm{S} 7 \dagger$ ). This result clearly means that a periodic arrangement of the axially chiral bithiophene units with a fixed syn-conformation presented here is important for helical folding.

To better understand the helix conformation of poly- $\mathrm{T}_{\mathrm{R}}$, its allatom MD simulation in chloroform was conducted using the corresponding model with a degree of polymerization of 20 (Fig. 5A). The initial structure with a left-handed helical backbone was constructed such that all neighboring thiophene pairs were arranged in syn-conformations. After equilibration at $298 \mathrm{~K}$ (see $\mathrm{ESI} \dagger$ ), the simulation in the microcanonical (NVE) ensemble was conducted for 2000 ps as the production run (Video S1 and S2 $\dagger$ ). The molecular models in the initial (0 ps) and final (2000 ps) states are shown in Fig. 5B-E. The molecular model in the middle (1000 ps) stage is shown in Fig. S8. $\dagger$ This simulation clearly demonstrated that the left-handed helically folded conformation, in which a single turn of the helix was composed of approximately 15 thiophene rings (Fig. S9†) and all sulfur atoms were arranged inside the helical cavity, remained unchanged after $2000 \mathrm{ps}$ and was probably the favorable conformation for poly- $\mathrm{T}_{\mathrm{R}}$ in chloroform. This computer-generated helix model was similar to that proposed by Kiriy et $a l^{46}$ Furthermore, the timedependent changes of three torsion angles $\left(\theta_{i}, \phi_{i}\right.$ and $\psi_{i}$, see Fig. 5A) between the two thiophene planes in the $i$ th repeating units from the terminal glucose-linked bithiophene unit were plotted, as shown in Fig. 6A-C. To reduce the influence of the chain ends, the results of the 18 repeating units $(i=2-19)$ were used for the discussion. The average torsion angles $\left(\bar{\theta}_{i}, \bar{\phi}_{i}\right.$ and $\left.\bar{\psi}_{i}\right)$ in the 20-mer model and their standard deviations (SD) are summarized in Table S1-S3. $\uparrow$ This statistics data revealed that the torsion angles in the glucose-linked bithiophene units $\left(\theta_{i}\right)$ were always negative, while the other two $\left(\phi_{i}\right.$ and $\left.\psi_{i}\right)$ were mostly positive with a few exceptions. In other words, three axial chirality arising in the repeating unit was not identical, and one $(\mathrm{a} R)$ - and two (aS)-configurations were arranged in the main chain, essentially in an alternating manner. Although the axial chirality in the main chain was inconsistent, all $\theta_{i}, \phi_{i}$ and $\psi_{i}$ values fell within the range of $-90^{\circ}$ to $+90^{\circ}$, suggesting that all pairs of neighboring thiophene planes perfectly retained their syn-conformations throughout the calculation period. For comparison, the righthanded helically folded model of poly- $\mathrm{T}_{\mathrm{R}}$ with all-syn conformations was constructed as an initial structure and its all-atom MD

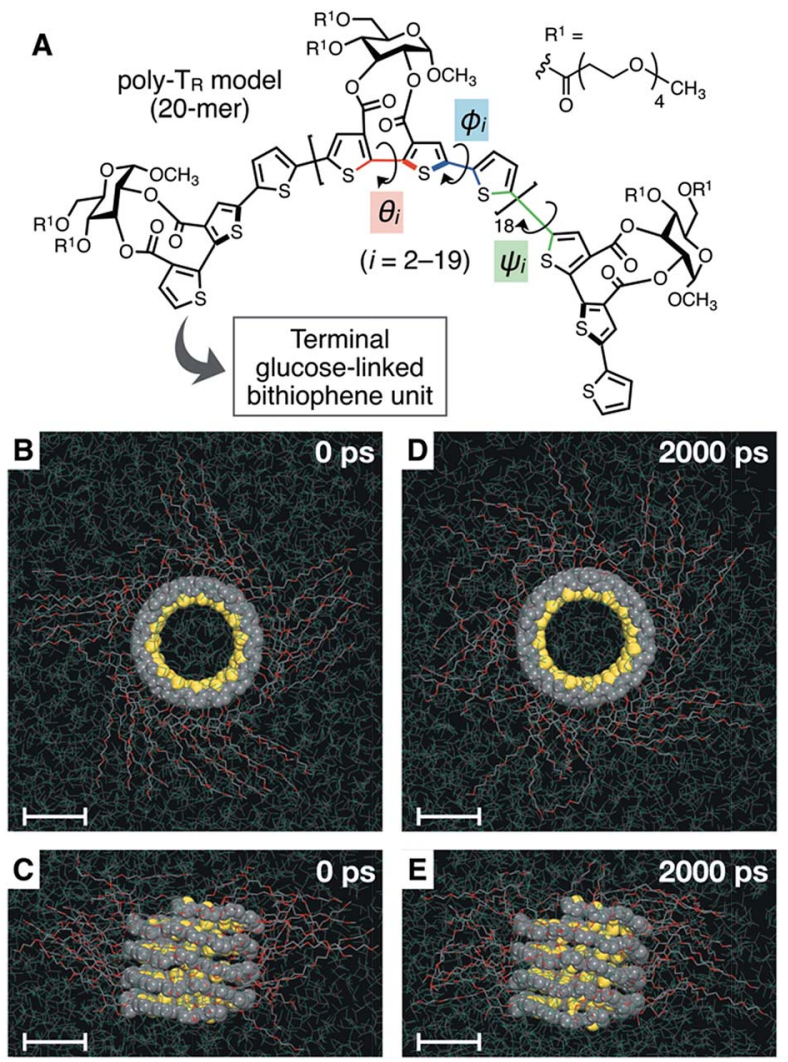

Fig. 5 (A) Structure of the poly- $T_{R}$ model (20-mer) used for the computational study. (B, D) Top view and (C, E) side view of the molecular model of left-handed helically folded poly- $T_{R}$ in chloroform at (B, C) 0 ps and (D, E) 2000 ps in an all-atom MD simulation after equilibration at $298 \mathrm{~K}$, represented by space-filling (polythiophene backbone) and stick (side chain) models. The chloroform solvent molecules are represented by line models and their hydrogen atoms are omitted to simplify the view. All scale bars represent $1 \mathrm{~nm}$.

simulation was conducted under the same conditions (Video S3 and $\mathrm{S} 4 \dagger$ ). In sharp contrast to the left-handed helix model, several anti-conformations were produced in the right-handed polythiophene backbones and the regular higher-order structure was not maintained during the calculation (Fig. S10†). This simulation supported that the plausible helix sense of poly- $T_{R}$ was lefthanded, as described above.

\section{Circularly polarized luminescence properties}

Fig. 7A shows photographs of poly- $\mathrm{T}_{\mathrm{R}}$ in chloroform and the solid state under $365 \mathrm{~nm}$ irradiation. Poly- $\mathrm{T}_{\mathrm{R}}$ exhibited an apparent orange photoluminescence (PL) in both states, which was attributed to the polythiophene backbone. The fluorescence quantum yield of poly- $\mathrm{T}_{\mathrm{R}}$ in chloroform was determined to be $5 \%$. The above chiroptical and PL properties of the optically active poly- $\mathrm{T}_{\mathrm{R}}$ allowed us to investigate its CPL performance. The PL, CPL and luminescence dissymmetry factor ( $\left.g_{\text {lum }}\right)$ spectra of poly- $\mathrm{T}_{\mathrm{R}}$ in chloroform are shown in Fig. 7B. Here, $g_{\text {lum }}=2\left(I_{\mathrm{L}}-I_{\mathrm{R}}\right) /\left(I_{\mathrm{L}}+I_{\mathrm{R}}\right)$, where $I_{\mathrm{L}}$ and $I_{\mathrm{R}}$ are the PL intensities of the left- and right-handed circularly polarized light, respectively. Poly- $\mathrm{T}_{\mathrm{R}}$ in chloroform emitted right-handed 

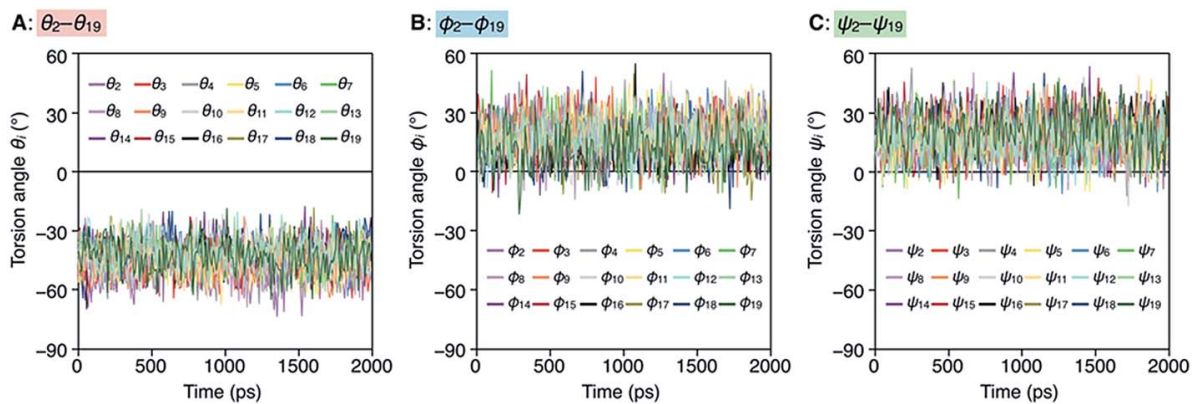

Fig. 6 Plots of $\theta_{i}(\mathrm{~A}), \phi_{i}(\mathrm{~B})$ and $\psi_{i}(\mathrm{C})$ as a function of calculation time.

circularly polarized light in the fluorescence region of the $\pi$ conjugated backbone, with the maximum $\left|g_{\text {lum }}\right|$ value estimated to be $1.6 \times 10^{-3}$, which was the same order as the maximum $\left|g_{\text {abs }}\right|$ value of poly- $\mathrm{T}_{\mathrm{R}}$ in chloroform $\left(4.3 \times 10^{-3}\right)$. This means that the helical structure in the ground state was likely retained in the excited state. Furthermore, we confirmed that the $\left|g_{\text {lum }}\right|$ of poly- $T_{R}$ was close to that observed for a previously reported helical polythiophene $\left(4.5 \times 10^{-3}\right)$ prepared through complexation with a polysaccharide. ${ }^{33}$ As expected from the $\mathrm{CD}$ comparison discussed above, the CPL performance of poly- $\mathrm{T}_{\mathrm{R}}$ was superior to that of model- $\mathrm{T}_{\mathrm{R}}$. Thus, we concluded that the helical conformation of

A

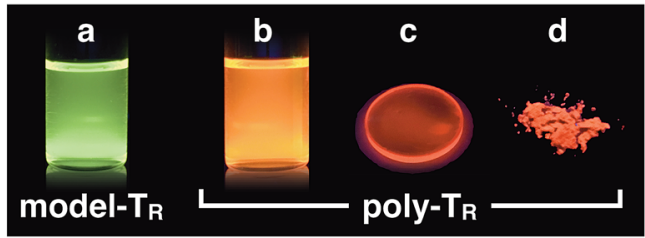

B

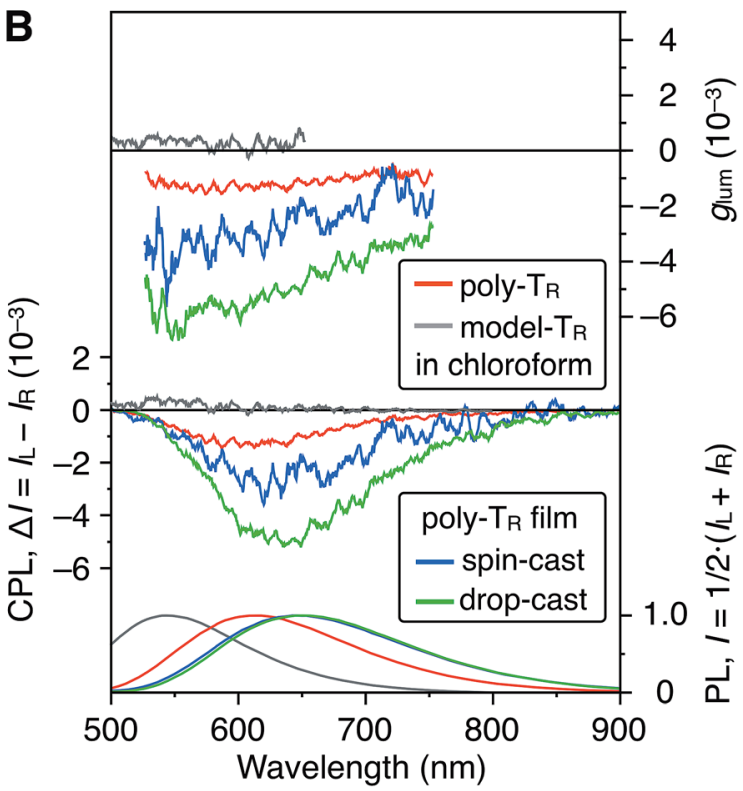

Fig. 7 (A) Photograph of chloroform solutions of (a) model- $T_{R}$ and (b) poly- $T_{R}$, and (c) the drop-cast film and (d) powder of poly- $T_{R}$ under irradiation at $365 \mathrm{~nm}$. (B) PL (bottom), CPL (middle) and $g_{\text {lum }}$ (top) spectra of poly- $T_{R}$ and model- $T_{R}$ in chloroform ([Glucose unit] $=1.0 \times$ $\left.10^{-4} \mathrm{M}\right)$ and the poly- $T_{R}$ films at room temperature. Excitation wavelength $\left(\lambda_{\text {ex }}\right), 365 \mathrm{~nm}$. the polythiophene backbone was of key importance for producing a moderate CPL. This statement was also supported by the fact that poly-Ph $\mathrm{Ph}_{\mathrm{R}}$ did not produce an apparent CPL signal (Fig. S11†). Next, to investigate the solid-state CPL performance, we prepared poly- $T_{R}$ films by drop- and spin-coating the chloroform solution onto quartz plates. ${ }^{47}$ The emission maximum wavelength in the film state was red-shifted by approximately $50 \mathrm{~nm}$ compared with the result in chloroform, which was due to elongation of the $\pi$ conjugation length. Furthermore, the poly- $\mathrm{T}_{\mathrm{R}}$ films showed better CPL performances than poly- $T_{R}$ in chloroform, with the maximum $\left|g_{\text {lum }}\right|\left(6.9 \times 10^{-3}\right)$ achieved by the drop-cast film in this study. The same tendency was also observed in the CD comparison between the solution and solid states (Fig. S14-S16†). A certain regular arrangement of helically folded poly- $\mathrm{T}_{\mathrm{R}}$ and its intermolecular couplet might be related to higher $g_{\text {abs }}$ and $g_{\text {lum }}$ values being achieved in the film state than in chloroform.

\section{Conclusions}

We have synthesized a new optically active polythiophene derivative (poly- $\mathrm{T}_{\mathrm{R}}$ ) containing $\mathrm{D}$-glucose-linked axially chiral bithiophene units with a syn-conformation in the main chain. Based on the comprehensive chiroptical study using poly- $\mathrm{T}_{\mathrm{R}}$, its analogous polymer and model compounds, we concluded that the poly- $T_{R}$ backbone possessed a specific secondary structure (helix) even under good solvent conditions, such as in chloroform, THF and chlorobenzene. Furthermore, all-atom MD simulations revealed that the probable helix sense of poly- $T_{R}$ was left-handed and a single helical turn was composed of approximately 15 thiophene rings. We also demonstrated that poly- $T_{R}$ can emit right-handed circularly polarized light due to the macromolecular helical chirality, with a maximum $\left|g_{\text {lum }}\right|$ value of $6.9 \times 10^{-3}$ reached in the film state. We believe that this helical polythiophene with an environment-independent folding feature represents a new category of advanced functional materials and is attractive for applications to organic electronics, sensors and host-guest systems through further modification of the backbone and pendant units. Further studies towards these goals are underway in our laboratory.

\section{Conflicts of interest}

There are no conflicts to declare. 


\section{Acknowledgements}

This work was supported by the Japan Society for the Promotion of Science (JSPS) KAKENHI through a Grant-in-Aid for Scientific Research (C) (Grant no. 17K05875) and WPI-NanoLSI Transdisciplinary Research Promotion Grant, Kanazawa University. Computation time for all-atom MD simulations was provided by the supercomputer system, Research Center for Advanced Computing Infrastructure, Japan Advanced Institute of Science and Technology (JAIST).

\section{Notes and references}

1 T. Yamamoto, K. Sanechika and A. Yamamoto, J. Polym. Sci., Polym. Lett. Ed., 1980, 18, 9-12.

2 J. W. P. Lin and L. P. Dudek, J. Polym. Sci., Polym. Lett. Ed., 1980, 18, 2869-2873.

3 J. Roncali, Chem. Rev., 1992, 92, 711-738.

4 R. D. McCullough, Adv. Mater., 1998, 10, 93-116.

5 H. S. O. Chan and S. C. Ng, Prog. Polym. Sci., 1998, 23, 11671231.

6 I. Osaka and R. D. McCullough, Acc. Chem. Res., 2008, 41, 1202-1214.

7 T. Yamamoto, NPG Asia Mater., 2010, 2, 54-60.

8 T. Higashihara and M. Ueda, Macromol. Res., 2013, 21, 257271.

9 M. Jaymand, M. Hatamzadeh and Y. Omidi, Prog. Polym. Sci., 2015, 47, 26-69.

10 I. F. Perepichka, D. F. Perepichka, H. Meng and F. Wudl, Adv. Mater., 2005, 17, 2281-2305.

11 H. A. Ho, A. Najari and M. Leclerc, Acc. Chem. Res., 2008, 41, 168-178.

12 C. B. Nielsen and I. McCulloch, Prog. Polym. Sci., 2013, 38, 2053-2069.

13 S. Agbolaghi and S. Zenoozi, Org. Electron., 2017, 51, 362403.

14 T. Pathiranage, D. S. Dissanayake, C. N. Niermann, Y. X. Ren, M. C. Biewer and M. C. Stefan, J. Polym. Sci., Part A: Polym. Chem., 2017, 55, 3327-3346.

15 J. G. Ibanez, M. E. Rincón, S. Gutierrez-Granados, M. Chahma, O. A. Jaramillo-Quintero and B. A. FrontanaUribe, Chem. Rev., 2018, 118, 4731-4816.

16 B. M. W. Langeveld-Voss, R. A. J. Janssen and E. W. Meijer, J. Mol. Struct., 2000, 521, 285-301.

17 F. J. M. Hoeben, P. Jonkheijm, E. W. Meijer and A. P. H. J. Schenning, Chem. Rev., 2005, 105, 1491-1546.

18 L. A. P. Kane-Maguire and G. G. Wallace, Chem. Soc. Rev., 2010, 39, 2545-2576.

19 M. Verswyvel and G. Koeckelberghs, Polym. Chem., 2012, 3, 3203-3216.

20 S. Matsushita, Y. S. Jeong and K. Akagi, Chem. Commun., 2013, 49, 1883-1890.

21 E. Yashima, N. Ousaka, D. Taura, K. Shimomura, T. Ikai and K. Maeda, Chem. Rev., 2016, 116, 13752-13990.

22 P. Wang, I. Jeon, Z. Lin, M. D. Peeks, S. Savagatrup, S. E. Kooi, T. Van Voorhis and T. M. Swager, J. Am. Chem. Soc., 2018, 140, 6501-6508.
23 C. X. Cui and M. Kertesz, Phys. Rev. B: Condens. Matter Mater. Phys., 1989, 40, 9661-9670.

24 M. Andersson, P. O. Ekeblad, T. Hjertberg, O. Wennerström and O. Inganäs, Polym. Commun., 1991, 32, 546-548.

25 K. P. R. Nilsson, M. R. Andersson and O. Inganäs, J. Phys.: Condens. Matter, 2002, 14, 10011-10020.

26 K. P. R. Nilsson, M. R. Andersson and O. Inganäs, Synth. Met., 2003, 135, 291-292.

27 K. P. R. Nilsson, J. D. M. Olsson, P. Konradsson and O. Inganäs, Macromolecules, 2004, 37, 6316-6321.

28 P. C. Ewbank, G. Nuding, H. Suenaga, R. D. McCullough and S. Shinkai, Tetrahedron Lett., 2001, 42, 155-157.

29 K. P. R. Nilsson and O. Inganäs, Nat. Mater., 2003, 2, 419424.

30 K. P. R. Nilsson, J. Rydberg, L. Baltzer and O. Inganäs, Proc. Natl. Acad. Sci. U. S. A., 2003, 100, 10170-10174.

31 K. P. R. Nilsson, J. Rydberg, L. Baltzer and O. Inganäs, Proc. Natl. Acad. Sci. U. S. A., 2004, 101, 11197-11202.

32 C. Li, M. Numata, M. Takeuchi and S. Shinkai, Chem.-Asian J., 2006, 1, 95-101.

33 S. Haraguchi, M. Numata, C. Li, Y. Nakano, M. Fujiki and S. Shinkai, Chem. Lett., 2009, 38, 254-255.

34 T. Shiraki, A. Dawn, Y. Tsuchiya and S. Shinkai, J. Am. Chem. Soc., 2010, 132, 13928-13935.

35 S. Tamaru, K. Hori and S. Shinkai, Chem. Lett., 2015, 44, 1667-1669.

36 J. R. Matthews, F. Goldoni, A. P. H. J. Schenning and E. W. Meijer, Chem. Commun., 2005, 5503-5505.

37 P. Leysen, J. Teyssandier, S. De Feyter and G. Koeckelberghs, Macromolecules, 2018, 51, 3504-3514.

38 H. H. Zhang, C. X. Ma, P. V. Bonnesen, J. H. Zhu, B. G. Sumpter, J. M. Y. Carrillo, P. C. Yin, Y. Y. Wang, A. P. Li and K. L. Hong, Macromolecules, 2016, 49, 4691-4698.

39 T. Ikai, S. Shimizu, S. Awata, T. Kudo, T. Yamada, K. Maeda and S. Kanoh, Polym. Chem., 2016, 7, 7522-7529.

40 T. Ikai, S. Awata, T. Kudo, R. Ishidate, K. Maeda and S. Kanoh, Polym. Chem., 2017, 8, 4190-4198.

41 T. Ikai, S. Minami, S. Awata, S. Shimizu, T. Yoshida, M. Okubo and K. Shinohara, Polym. Chem., 2018, 9, 55045510.

42 T. Ikai, S. Shimizu, S. Awata and K. Shinohara, Macromolecules, 2018, 51, 2328-2334.

43 T. Ikai, S. Awata and K. Shinohara, Polym. Chem., 2018, 9, 1541-1546.

44 E. Yashima, K. Maeda, H. Iida, Y. Furusho and K. Nagai, Chem. Rev., 2009, 109, 6102-6211.

45 T. Ikai, S. Shimizu, T. Kudo, K. Maeda and S. Kanoh, Bull. Chem. Soc. Jpn., 2017, 90, 910-918.

46 N. Kiriy, E. Jähne, H.-J. Adler, M. Schneider, A. Kiriy, G. Gorodyska, S. Minko, D. Jehnichen, P. Simon, A. A. Fokin and M. Stamm, Nano Lett., 2003, 3, 707-712.

47 We confirmed that the influence of optical anisotropy on the films was almost negligible (Fig. S12 and S13†). 